\title{
Risk Analysis and Evaluation of Capital Investment Projects
}

\section{J H Hall}

Department of Accounting and Finance, University of Pretoria

\section{ABSTRACT}

In determining the feasibility of projects where capital investments are concerned, various methods are used. The focus of these methods is on return per se, so it is often asked to what extent any of these methods take the risk concept into account. The main objective of this study was to investigate the importance of risk with regard to capital investment projects. Secondly, with the aid of an empirical study, the study tried to establish whether risk is incorporated when South African companies evaluate capital investment projects. The empirical analysis indicated that risk analysis and evaluation in practice are to a large extent neglected by South African companies. It was found that nearly a quarter of companies estimate their annual cash flows using management subjective estimates alone.

JEL M 21

\section{INTRODUCTION}

The evaluation of capital investment projects can be regarded as one of the most important tasks of any financial manager. Undertaking and accepting viable investments is crucially important, not only for the long-term growth of a firm and the creation of shareholder wealth, but also the creation of wealth for the inhabitants of a country.

The substance of capital investment evaluation methods is retum per se, but it is often asked to what extent any of these methods takes risk into account. It may be argued that the discount rate used in the application of these methods does take the relevant risk factors into account, and that no further risk assessments should be deemed necessary. The main problem with this point of view, however, is that the discount rate used is often subjectively determined. In some cases, the discount rate is derived from a weighted average cost of capital (WACC), which refers to the required rate of return in a specific company. Although this is not incorrect, one should realize that the WACC of a particular 
project may be quite different from that of the company evaluating the project, thus resulting in either a higher or lower required rate of return being used in the evaluation process.

There are different methods to evaluate capital investment decisions. The feasibility of a capital investment project should therefore not only be determined by evaluating the expected rate of return of such a project, but the risks which impact on the outcome of the investment decision should also be considered.

\section{RESEARCH OBJECTIVES}

The primary objective of this paper is to investigate the importance of risk evaluation in capital investment projects, and to formulate guidelines for the application of such an approach. This is done by means of a literature study. Secondly, with the aid of an empirical study, the paper also tries to establish whether risk is incorporated in the evaluation of capital investment projects by South African companies.

The hypotheses tested in this study are the following:

\section{Hypothesis 1:}

Although there are different approaches in the determination of risk, companies in general do not follow these approaches in making to their capital investment decisions.

\section{Hypothesis 2:}

The incorporation of risk in the capital budgeting decision should not be altered by the size of the capital budget.

\section{Hypothesis 3:}

Companies do make adjustment for inflation when analyzing capital investment decisions.

\section{THE CAPITAL INVESTMENT DECISION}

\subsection{Concept Definition: Risk}

The term risk has many different meanings today. In financial circles, however, risk has a definite and distinctive meaning. Risk refers to the situation where decisions are based on the calculation of probabilities that alternative outcomes 
will materialize, or where probabilities, based on historical information and statistical frequency distributions, are known.

The relationship between risk and capital investment decisions is well described by Petersen (1994: 463). She states with regard to capital investment opportunities that

“... for an evaluation of any investment to be meaningful, we must represent how much risk there is so that the cash flows of an investment will differ from what is expected in terms of their amount and timing. Risk is the degree of uncertainty".

The execution of the capital investment decision thus requires the decisionmaker to evaluate and analyze the risks involved. It requires a systematic evaluation of capital investment proposals. Poor decisions may have an enormous negative impact on the profitability of a firm, as decisions usually cannot be revoked.

To address risks, the financial manager should adjust his/her capital investment decisions in one of the following two ways: either the required rate of return should be adjusted to provide for the additional risk involved, or an adjustment should be made to the relevant cash flows.

Various techniques are used to evaluate investment opportunities. The most important techniques are: Internal Rate of Return (IRR), Present Value Payback (PVP), Accounting Rate of Return (ARR), the Profitability Index (PI), and Net Present Value (NPV). Theoretically, risk can be incorporated or accounted for in each of these methods, when they are applied to evaluate the capital investment decision.

The question of how management should go about evaluating the risk associated with capital investment decisions is next addressed. A number of techniques to incorporate risk in the capital budgeting decision are briefly discussed.

\subsection{Mean, Variance and Coefficient of Variation}

The calculation of the mean, variance and coefficient of variation is a very widespread method and relatively easy to use in the evaluation of risk. With the computation of the coefficient of variation and the correlation coefficient, the relative risk of the projects concemed can be compared. The lower the coefficient of variation, the smaller the degree of relative risk. 


\subsection{Certainty Equivalent Method}

The certainty equivalent method is a recognized technique for the adjustment of risk in capital investment decisions. It is a method based on the principle that risky cash flows can be converted into corresponding risk-free cash flows. It is therefore an adjustment of cash flow estimates. The method allows for risk preferences to be included in the investment decision, as each risky cash flow is converted into its risk-free equivalent by multiplying it with a conversion factor. The decision-making rule which applies when this method is used for capital investment decisions, is that if the certainty equivalent NPV is greater than or equal to zero, the project can be accepted.

\subsection{Risk-Adjusted Discount Rate Method}

The risk-adjusted discount rate method for investment projects is relatively simple and consequently widely used. The method is based on the assumption that adjustments for risks associated with capital investment projects can be made by means of the discount rate or cost of capital. The expected cash flow is discounted at a rate that both provides for the time value of money and shows the risk of the cash flow of projects. The adjustment for risk thus requires the expected risk for cash flows to be discounted at a higher discount rate than when the probability distribution of expected cash flows (and hence risk) is relatively smaller.

\subsection{Sensitivity Analysis}

Sensitivity analysis is used in order to improve the accuracy and reliability of cash flows. It requires the examination of the sensitivity of some variable to changes in another variable. The primary purpose of sensitivity analysis is not to quantify risk, but to establish how sensitive the NPV and the IRR are to changes in the values of key variables in the evaluation of investment projects.

\subsection{Computer Simulation}

Unlike sensitivity analysis, computer simulation allows the evaluation of the impact of changes in several variables simultaneously. Some elaborate computer programmes even perform analyses that cover the entire distribution of potential outcomes. Computer simulation may result in highly complex models, as interdependencies amongst variables need to be recognized if the model is to reflect reality. One of the most popular simulation models is the Monte Carlo model. 
It may be concluded that the evaluation of risk in order to maximize shareholder wealth is an essential and difficult task. The present empirical study was conducted in order to determine how South African firms evaluate risk and whether they incorporate risk in making their capital investment decisions. The next section sets out the method used in conducting the empirical study.

\section{RESEARCH METHOD}

\subsection{Comparative Studies}

One of the key decision areas facing the contemporary financial manager, namely the capital investment decision and the results derived from it, is central in moulding a firm's future opportunities. Academics have, over the years, pleaded the use of more sophisticated approaches to capital investment analysis, and it has been strongly suggested that adjustments for risk should be made.

Various studies have been conducted in the USA into the techniques of evaluating risk in capital investment decisions. Gitman and Forrester (1977: 6671) found that 71 per cent of their respondents explicitly took into account risk and uncertainty. It was moreover found that 42.7 per cent of these respondents adjusted for risk by increasing the minimum rate of return or the cost of capital. The popularity of the risk-adjusted rate of return is not supprising, since it is one of the easiest approaches available for risk adjustment. However, a major problem with this approach is that the adjustment for risk can itself be subjective, seeing that risk cannot be quantified precisely in all cases.

In a similar study by Jog and Srivastava (1995: 37-43) in Canada in 1991, the use of subjective, judgmental, and non-standard techniques in the estimation of cash flows were found to be relatively high. In addition, nearly a quarter of their respondents did not have a formal risk analysis technique in place.

Similar studies have also been conducted in South Africa. The two most prominent were undertaken in 1986 by Andrews and Butler (1986: 31-37) and by Parry and Firer (1990: 52-58). With regard to firms adjusting for risk and uncertainty, Andrews and Butler found that nearly 25 per cent of the firms responding were using subjective judgment alone to allow for risk. It is of particular concern that they found a wide gap between theory and practice, with nearly a quarter of their respondents (apart from the 25 per cent who only use subjective judgment) stating that they made no allowance for risk and uncertainty. The research found that increased sophistication of the capital investment process correlated positively with a firm's performance. 
The study by Parry and Firer (1990) found that approximately one third of their respondents did not use any quantitative technique to assess risk or adjust for it. Of the remainder, almost all respondents used the relatively unsophisticated sensitivity analysis technique. Although few firms used sophisticated methods of risk adjustment, it transpired that capital intensive firms made greater use of quantitative risk-analysis tools. Most of these companies used the IRR as the chief method.

\subsection{Description of the Population}

The population chosen was companies listed in the Industrial Sector of the Johannesburg Securities Exchange (JSE). Industrial companies were selected for the research because the capital investment decision figures relatively prominently in these companies as it closely relates to production capacity.

\subsection{Source of Data}

The information used in this study was obtained in collaboration with the Bureau of Financial Analysis at the Graduate School of Management of the University of Pretoria. A questionnaire was sent to the selected sample.

\subsection{Sample Selection}

There were 358 companies in the Industrial Sector on the JSE when the study was done in 1998. Given financial and time constraints, these companies were listed alphabetically and only the first 300 were selected in the sample.

\subsection{Questionnaires}

The questionnaire consisted of 24 questions divided into three sections. The first section pertains to the company and decision-maker profile, necessary to categorize the data from the various responses. Section two examined the capital budgeting techniques used in the investment process with specific reference to the techniques most often used in assessing the viability of different operations. The results of these sections were dealt with in a previous article (Hall, 2000: 353-68). The present article deals with the third section, which examined the various techniques used for risk evaluation. This section comprised five questions.

\subsection{Data Collection and Analyses}

As was stated above, an address list of all the companies in the Industrial Sector of the JSE was made available by the Bureau of Financial Analysis at the 
Graduate School of Management of the University of Pretoria. Questionnaires were sent to 300 companies, during the second half of 1998. Responses were encoded with the assistance of the Graduate School of Management. The data were computerized using the computer software package SAS (Statistical Analysis System). A spreadsheet reflecting the respondents' answers was compiled and encoded for use as input into the SAS-programme.

\section{EMPIRICAL RESULTS}

\subsection{Introduction}

In analyzing the data from the questionnaires, it was found that although the majority of questions only have one logical answer, the respondents sometimes selected more than one answer. In order to apply a consistent approach in capturing the data, the first answer given to a specific question was regarded as the respondent's answer for this purpose.

\subsection{Response}

The total response from the population of 300 amounted to 70 questionnaires ( 23.3 per cent), which were categorized as "usable" and "non-usable" responses. The "usable" responses amounted to 65 questionnaires, giving a response rate of 21.7 per cent. In analyzing the data, it was found that the questionnaires had been completed mainly by the financial directors of the various companies ( 55.4 per cent). Completion by financial managers amounted to 29.2 per cent, while the remaining 15.4 per cent were completed by either the chief executive officer ( 7.7 per cent), the company secretary ( 2.5 per cent), the treasurer ( 1.5 per cent) or other senior management ( 3.7 per cent). The majority of the respondents (13.8 per cent) were in the Stores sector while 12.3 per cent indicated that they were in the Industrial Holdings sector and a further 12.3 per cent were in the Food sector.

Table 1 below illustrates the respondents' annual sales and the size of the annual capital budget.

Annual sales were more than R100 million for 83.1 per cent of the respondents, while 41.5 per cent of the respondents' annual capital budget was more than R50 million ( 24.6 per cent more than R100 million and 16.9 per cent between R50 million and R100 million). The importance of the capital investment decision can thus be clearly seen when one analyses the amount spent on capital investment projects. For instance, if 24.6 per cent of the 65 respondents, as 
indicated, spent more than R100 million on their annual capital budget, it amounts to more than R1.6 billion in capital investments per annum.

Table 1 Annual sales and size of annual capital budget

\begin{tabular}{|l|c|c|}
\hline \multicolumn{1}{|c|}{ Item } & Annual Sales & $\begin{array}{c}\text { Annual } \\
\text { Capital budget }\end{array}$ \\
\hline Less than R2 million & 0.00 & 10.80 \\
Between R2 million and R5 million & 1.50 & 12.30 \\
Between R5 million and R10 million & 0.00 & 12.30 \\
Between R10 million and R25 million & 0.00 & 12.30 \\
Between R25 million and R50 million & 4.60 & 10.80 \\
Between R50 million and R100 million & 10.80 & 16.90 \\
More than R100 million & 83.10 & 24.60 \\
\hline & $100 \%$ & $100 \%$ \\
\hline
\end{tabular}

\subsection{Interpretation and Discussion of Results}

Respondents were asked to indicate which risk analysis techniques they used when analyzing risk with regard to capital investment decisions. Table 2 shows that 36.9 per cent of respondents do not make use of any formal technique. This finding is significant since it means that these respondents do not make any allowances for risk.

\section{Table 2 Risk analysis techniques}

\begin{tabular}{|l|c|c|}
\hline \multicolumn{1}{|c|}{ Risk analysis technique } & Percentage & Ranking \\
\hline & & \\
No formal technique in use & 36.90 & 1 \\
Sensitivity analysis & 30.80 & 2 \\
Adjusting required rate of return & 12.30 & 3 \\
Shortening payback period & 6.20 & 4 \\
Standard deviation & 4.60 & 5 \\
Simulation & 4.60 & 5 \\
Probability theory & 1.50 & 6 \\
Calculated bail-out factor & 1.50 & 6 \\
Other & 1.50 & 6 \\
\hline N=65 & $100 \%$ & \\
\hline
\end{tabular}


As stated above, sensitivity analysis is used to improve the accuracy and reliability of cash flows. The primary purpose of sensitivity analysis is not to quantify risk, but to establish how sensitive the NPV and the IRR are to changes in the values of key variables in the evaluation of investment projects. The fact that 30.8 per cent of the respondents indicated that they use sensitivity analysis as a risk analysis technique may seem to be an anomaly. Although the primary purpose of sensitivity analysis is not to quantify risk, its use as indicated by respondents, enables them to determine the sensitivity of key variables to changes in the operating environment. In this context, larger companies indirectly recognize the importance of return related risks in sensitivity analysis. Although the risks per se are not quantified, sensitivity analysis offers companies a relatively easy and cost-effective method to adjust for return related risks associated with capital investment decisions as they can assess influences on key outputs of the investment process and assist with decision making.

Another interesting finding was that none of the respondents indicated that they used variance, coefficient of variances, decision trees, Monte Carlo simulation or the certainty equivalent method in risk analysis.

Similar results were found in a UK study by Pike (Lumby, 1991: 494), which indicated that only 37 per cent of companies analyzed risk formally. For these, sensitivity analysis and the risk adjusted discount rate were equally popular. When the 67 per cent of sample firms which did not use risk analysis were asked why they did not do so, some rather confused reasons were given, such as: "risk was impossible to quantify" "too time-consuming", "too complex" and "such an analysis brought undesirable negative pressure on decision-makers and went against the true entrepreneurial approach".

An analysis of the respondent's answers according to the size of their annual capital budget as illustrated in Table 3, shows that the majority of companies with an annual capital budget exceeding R50 million used sensitivity analysis as a risk analysis technique. The majority of companies with an annual capital budget between R10 million and RS0 million did not use a formal risk technique, although the use of sensitivity analysis was relatively high. An interesting finding is that companies with an annual capital budget below R5 million, to a large extent, did not make use of any formal risk technique. A tendency can thus be observed to the effect that the larger the size of a company's annual capital budget, the more that company is inclined to rely on sensitivity analysis as a formal risk analysis technique. It can thus also be concluded that the smaller a company's annual capital budget, the less it is inclined to use any formal risk technique. 
Table 3 Risk analysis technique according to annual capital budget

\begin{tabular}{|c|c|c|c|c|c|c|c|}
\hline $\begin{array}{l}\text { Risk analysis } \\
\text { technique }\end{array}$ & $\begin{array}{l}\text { More } \\
\text { than } \\
\text { R100m } \\
(\mathrm{n}=16)\end{array}$ & $\begin{array}{c}\mathrm{R} 50 \mathrm{~m} \\
\text { to } \\
\mathrm{R} 100 \mathrm{~m} \\
(\mathrm{n}=11)\end{array}$ & $\begin{array}{c}\text { R25m } \\
\text { to } \\
\text { R50m } \\
(\mathrm{n}=7)\end{array}$ & $\begin{array}{c}\text { R10m } \\
\text { to } \\
\text { R25m } \\
(n=8)\end{array}$ & $\begin{array}{c}\text { R5m } \\
\text { to } \\
\text { R10m } \\
(\mathrm{n}=8)\end{array}$ & $\begin{array}{c}\mathbf{R} 2 \mathrm{~m} \\
\text { to } \\
\text { R5m } \\
(\mathrm{n}=8)\end{array}$ & $\begin{array}{l}\text { Less } \\
\text { than } \\
\mathbf{R} 2 \mathrm{~m} \\
(\mathrm{n}=7)\end{array}$ \\
\hline $\begin{array}{l}\text { No formal technique } \\
\text { in use }\end{array}$ & 25.0 & 27.3 & 42.8 & 37.5 & 12.5 & 50.0 & 85.7 \\
\hline Sensitivity analysis & 37.4 & 45.4 & 28.6 & 37.5 & 25.0 & 25.0 & 0.0 \\
\hline $\begin{array}{l}\text { Adjusted required } \\
\text { rate of return }\end{array}$ & 12.5 & 18.2 & 14.3 & 12.5 & 25.0 & 0.0 & 0.0 \\
\hline $\begin{array}{l}\text { Shortening payback } \\
\text { period }\end{array}$ & 6.3 & 0.0 & 0.0 & 0.0 & 25.0 & 12.5 & 0.0 \\
\hline Standard deviation & 12.5 & 0.0 & 0.0 & 0.0 & 12.5 & 0.0 & 0.0 \\
\hline Simulati & 6.3 & 0.0 & 0.0 & 12.5 & 0.0 & 12.5 & 0.0 \\
\hline Probability theory & 0.0 & 0.0 & 14.3 & 0.0 & 0.0 & 0.0 & 0.0 \\
\hline $\begin{array}{l}\text { Calculated bail-out } \\
\text { factor }\end{array}$ & 0.0 & 0.0 & 0.0 & 0.0 & 0.0 & 0.0 & 14.3 \\
\hline Other & 0.0 & 9.1 & 0.0 & 0.0 & 0.0 & 0.0 & 0.0 \\
\hline & 100 & 100 & 100 & 100 & 100 & 100 & 100 \\
\hline
\end{tabular}

Respondents were asked to indicate which adjustments they made to accommodate possible fluctuations in the inflation rate. Rappaport \& Taggart (Aggarwal, 1993: 18) stated that the effects of inflation on the various cash flows and on the discount rate should have a negative impact on the attractiveness of capital expenditure.

From the summary in Table 4 it can be seen that the majority of companies use various inflation rates for different annual cash flows (55,4 per cent), indicating an adjustment for inflation effects on cash flows of investment projects.

Although 18.5 per cent of respondents indicated that they use a single inflation rate for different annual cash flows, this percentage rate may indicate that the risk associated with the effect of inflation on the cash flows of investment projects is, to a large extent, ignored. Also, 23.1 per cent of the respondents did not make any allowances for inflation when estimating their future cash flows. 
Table 4 Adjustments made to accommodate fluctuations in the inflation rate

\begin{tabular}{|l|c|}
\hline \multicolumn{1}{|c|}{ Item } & Percentage \\
\hline & \\
No allowances are made for inflation & 23.10 \\
Use various inflation rates for different annual cash flows & 55.40 \\
Use a single inflation rate for different annual cash flows & 18.50 \\
Other & 3.10 \\
\hline & $100 \%$ \\
\hline
\end{tabular}

Table 5, where the adjustments made for inflation are summarized according to the size of the respondents' annual capital budget, shows that the majority of all respondents (irrespective of the size of their annual capital budget) used various inflation rates for different annual cash flows in order to make adjustments for inflation. Among companies with an annual capital budget less of than R2 million, the trend was to use a single inflation rate for different annual cash flows.

Table 5 Inflation adjustments according to annual capital budget

\begin{tabular}{|c|c|c|c|c|c|c|c|}
\hline Risk analysis technique & $\begin{array}{l}\text { More } \\
\text { than } \\
\text { R100m } \\
(\mathrm{n}=16) \\
\end{array}$ & $\begin{array}{c}\mathbf{R 5 0 m} \\
\text { to } \\
\mathbf{R} 100 \mathrm{~m} \\
(\mathrm{n}=11) \\
\end{array}$ & $\begin{array}{c}\mathbf{R 2 5 m} \\
\text { to } \\
\mathbf{R 5 0 m} \\
(\mathrm{n}=7)\end{array}$ & $\begin{array}{l}\mathbf{R} 10 \mathrm{~m} \\
\text { to } \\
\mathbf{R} 25 \mathrm{~m} \\
(\mathrm{n}=8)\end{array}$ & $\begin{array}{c}\mathbf{R 5 m} \\
\text { to } \\
\text { R10m } \\
(\mathrm{n}=8)\end{array}$ & $\begin{array}{l}\mathrm{R} 2 \mathrm{~m} \\
\text { to } \\
\mathbf{R} 5 \mathrm{~m} \\
(\mathrm{n}=8)\end{array}$ & $\begin{array}{l}\text { Less } \\
\text { than } \\
\text { R2m } \\
(n=7)\end{array}$ \\
\hline $\begin{array}{l}\text { No allowances made } \\
\text { for inflation }\end{array}$ & 25.0 & 27.3 & 0.0 & 50.0 & 25.0 & 0.0 & 28.5 \\
\hline $\begin{array}{l}\text { Various inflation } \\
\text { rates different annual } \\
\text { cash flows }\end{array}$ & 56.3 & 45.4 & 71.4 & 50.0 & 37.5 & 100 & 28.5 \\
\hline $\begin{array}{l}\text { Single inflation rate } \\
\text { different annual cash } \\
\text { flows }\end{array}$ & 12.5 & 27.3 & 14.3 & 0.0 & 37.5 & 0.0 & 43.0 \\
\hline Other & 6.2 & 0.0 & 14.3 & 0.0 & 0.0 & 0.0 & 0.0 \\
\hline & 100 & 100 & 100 & 100 & 100 & 100 & 100 \\
\hline
\end{tabular}

Westwick and Shohet (Lumby, 1991: 493) found that 77 per cent of their sample attempted to take inflation into account, whilst Pike (Lumby, 1991: 493) found that 89 per cent of companies considered inflation in investment appraisal. 


\section{SUMMARY OF RESULTS AND RECOMMENDATION}

\subsection{Summary of Results}

The results of the first part of this study were reported in a previous article (Hall, 2000: 353-68) and indicate that South African companies prefer ROI and IRR as methods to determine the feasibility of capital investment projects.

The results reported in the present article indicate that risk analysis and evaluation in practice is, to a large extent, neglected by South African companies. The research results show that nearly a quarter of companies estimated their cash flows using subjective estimates by management alone, while 36.9 per cent of respondents explicitly stated that they used no formal risk analysis technique in the evaluation of capital investment projects. There is a correlation between the size of a company's annual capital budget and the technique used by that company: The larger the annual capital budget, the more a company tends to use sensitivity analysis, while smaller companies tend not to use any formal risk technique.

Although the primary purpose of sensitivity analysis is not to quantify risk, but to determine the sensitivity of key variables to changes in the operating environment, larger companies indirectly recognize the importance of retumrelated risks in applying sensitivity analysis. Although the risks per se are not quantified, sensitivity analysis offers companies a relatively easy and costeffective method to adjust for return related risks associated with capital investment decisions. Hence the popularity of this approach.

Many South African companies do not make adjustments for the inflation rate when assessing the viability of a capital investment project. This can be clearly seen in the estimation of future annual cash flows, where the research found that nearly a quarter of companies do not make any adjustment for inflation. Although the majority of companies do use various inflation rates for different annual cash flows, 18.5 per cent used a single inflation rate for different annual cash flows, while 23 per cent made no adjustment. Again, it seems the latter applies more to companies with an annual capital budget less than R2 million. This corresponds to the fact that smaller companies also tend not to make any allowances for risk.

It therefore seems that smaller companies in particular do not analyze or evaluate return-related risks associated with capital investment projects. Although larger companies make an effort to at least identify the risk factors likely to influence the outcome of their investment decisions, the quantification of risk per se is neglected in South Africa. This is a cause of great concern, 
especially if the large Rand value of capital investments in the South African economy is taken into account.

Financial decision-makers in South African companies are highly qualified personnel; the majority have post-graduate qualifications. The failure to quantify risk by the available techniques is therefore not necessarily a result of ignorance, but should rather be attributed to the difficulty of quantifying returnrelated risks. The fact that companies operate in a dynamic environment exposes them to continuous change, where key risk factors change constantly, adding to the difficulties associated with the use of scientifically sound methods of quantifying risk.

In testing the hypotheses under Research Objectives above, the following were found:

Hypothesis 1 tested positive. Approaches to the determination of risk and their application to capital investment decisions are generally not used by South African companies.

Hypothesis 2 tested negative. Companies with a smaller capital budget make even less use of risk-adjusted methods in evaluating capital investment decisions than companies with a relatively larger capital expenditure programme.

Hypothesis 3 tested positive. Nearly 56 per cent of companies make adjustment for inflation in the capital budgeting process.

\subsection{Recommendations}

In order to enable decision-makers to analyze and evaluate return-related risks associated with capital investment projects more effectively, the following recommendations are suggested for further investigation:

As there is no single statistically sound and scientifically correct approach to the analysis and evaluation of capital investment projects, academics and practitioners should strive to find an approach that would at least enable them to progress in that direction. The development of such a model should assist both small and large companies to quantify the risks associated with the capital investment decision, helping financial decision-makers to manage investments more efficiently.

The neglect of risk factors occurs mainly in smaller companies, and the construction of a model ought to be investigated which would enable them to quantify and measure risk. This model should be simple to use. It should be 
based on a matrix where techniques or formulas are applied which would make it possible for decision-makers to weigh the consequences of failure against the probability of failure, by establishing values on the matrix. The development of such a model should be investigated especially for use by non-listed companies.

With regard to the education of postgraduate students, there should be an emphasis on the practical application of risk analysis techniques, with a view to encouraging the more general application of such techniques.

\section{ENDNOTE}

The author would like to thank Mr PG Vosloo and Prof LM Brümmer for their inputs.

\section{REFERENCES}

1 AGGARWAL, R. (1993) Capital Budgeting under Uncertainty. Englewood Cliffs, New Jersey: Prentice-Hall, 292p.

2 ANDREWS, G.S. \& BUTLER, F. (1986) "Criteria for Major Investment Decisions", The Investment Analysts Journal, May 1986: 31-7.

3 GITMAN, L.J. \& FORESTER, J.R. Jr. (1977) "Forecasting and Evaluation: Practices and Performance, a Survey of Capital Budgeting Techniques Used by Major U.S. Firms", Financial Management, Fall: 6671.

4 HALL, J.H. (2000) "Investigating Aspects of the Capital Budgeting Process used in Investment Projects", South African Journal of Economic and Management Sciences, (3)3: 353-68, September 2000.

5 JOG, V.M. \& SRIVASTAVA, A.K. (1995) "Capital Budgeting Practices in Corporate Canada", Financial Practice and Education, Fall/Winter: 37. 43.

6 LUMBY, L. (1991) Investment Appraisal and Financing Decisions ( $4^{\text {th }}$ ed.) London: Chapman \& Hall, $518 \mathrm{p}$.

7 PARRY, H.M.A. \& FIRER, C. (1990) "Capital Budgeting under Uncertainty an Empirical Study", South African Journal of Business Management, 21(3): 52-8.

8 PETERSEN, P.P. (1994) Financial Management and Analysis, New York: McGraw-Hill, 864p. 